\title{
O PENSAMENTO POLÍTICO EDUCACIONAL DE ANTONIO GRAMSCI ANTES DOS CADERNOS DO CÁRCERE
}

\author{
THE EDUCATIONAL POLITICAL THOUGHT OF ANTONIO GRAMSCI BEFORE PRISON THE POLITICAL
} NOTEBOOOKS

EL PENSAMIENTO POLÍTICO EDUCATIVO DE ANTONIO GRAMSCI ANTES DE LOS CUADERNOS DE LA CÁRCEL

CARMO, Jefferson Cariello do ${ }^{1}$

\section{RESUMO}

O objetivo deste texto é examinar no semanário L'Ordine Nuovo, no período entre 1919 a 1920, a questão educacional após o primeiro grande conflito. Esta preocupação centra-se na análise de alguns documentos escritos para o referido jornal, no período indicado. $\mathrm{O}$ artigo pretende ser uma contribuição, sumária e introdutória, de alguns dos aspectos do pensamento político educacional do filósofo italiano Antonio Gramsci, no contexto da crise e revolução italiana.

Palavras-chave: Política Educacional. História da educação. Antonio Gramsci. Educação e Trabalho.

\section{ABSTRACT}

The aim of this text is to examine the weekly L'Ordine Nuovo in the period between 1919-1920, the educational issue after the first major conflict. This concern focuses on the analysis of some written documents for the aforementioned newspaper, in the indicated period. The article intends to be a contribution, summary and introductory of some of the aspects of the educational political thought of the Italian philosopher Antonio Gramsci, in the context of the Italian crisis and revolution.

Keywords: Educational Policy. History of Education. Antonio Gramsci. Education and Work.

\section{RESUMEN}

El propósito de este trabajo es examinar el semanario L'Ordine Nuovo, en el periodo comprendido entre 1919 a 1920, la cuestión educativa después del primer conflicto importante. Esta preocupación se centra en el análisis de algunos documentos escritos para el Diario, en el período. El artículo es una contribución, el resumen y la introducción de algunos aspectos de la política educativa pensamiento del filósofo italiano Antonio Gramsci, en el contexto de la crisis y la revolución italiana.

Palabras clave: Política para la Educación. Historia de la Educación. Antonio Gramsci. Educación y Trabajo.

\footnotetext{
1 Universidade de Sorocaba - UNISO - Sorocaba - São Paulo - Brasil
} 


\title{
CONSIDERAÇÕES INICIAIS
}

O pensamento político e educacional de Antonio Gramsci tem sido no Brasil há algumas décadas uma referência teórica para muitos estudos da realidade educacional brasileira. Nota-se que essa menção, no âmbito educacional, encontra apego com mais frequência, nos Cadernos do Cárcere, cuja consequência é quase um "esquecimento" dos outros escritos anteriores aos Cadernos. A necessidade do alcance do seu pensamento político/educacional antes e depois dos Cadernos se faz necessário, por meio, de uma leitura que procure desvendar sua preocupação teórica/prática e analítica sobre a questão educacional. Em conformidade com as ideias de Lombardi (1972) ao referirse sobre a escola e o mundo do trabalho nos escritos anteriores aos Cadernos afirma a necessidade de leitura desses textos com a finalidade de identificar no conteúdo os elementos pedagógicos, educacionais e políticas, contidos neles

\begin{abstract}
[...] con el fin de garantizar la participación activa del educando en la conquista del saber, proyecta la necesidad de incluir, ya desde las clases elementales, el trabajo en la escuela, en cuanto "el concepto y el hecho del trabajo (de la actividad teórico práctica) es el principio educativo inmanente a la escuela elemental, porque el orden social y estatal (derechos y deberes) es introducido por el trabajo e identificado en el orden natural. El concepto de equilibrio entre orden social y natural en el fundamento del trabajo, de la actividad teórico-práctica del hombre, crea los primeros elementos de una visión del mundo liberada de magia y brujería, y da paso al desarrollo de una concepción histórica, dialéctica del mundo, para comprender el movimiento y el transformarse, para valorar la suma de esfuerzos y sacrificios que ha costado el presente al pasado, para concebir la actualidad como síntesis del pasado, de todas las generaciones pasadas, y que se proyectan en el futuro. (LOMBARDI, 1972, p. 74).
\end{abstract}

O que estamos propondo, neste texto, é examinar alguns escritos no período entre 1914 a 1919, com destaque nos jornais do semanário L'Ordine Nuovo, sobre a questão educacional e política no contexto da crise italiana, após o Primeiro Grande Conflito. Esta preocupação centra-se na análise de alguns documentos escritos para o referido jornal, no período indicado. $\mathrm{O}$ artigo pretende ser uma contribuição, sumária e introdutória, de alguns dos aspectos do pensamento político e educacional do filósofo italiano Antonio Gramsci, no contexto da crise e revolução italiana, antes dos Cadernos.

\section{O SITZ IM LEBEN DO L' ORDINE NUOVO}

Nas palavras de Buzzi (apud. 1969, p. 17) ao referir-se sobre o progreso del pensamento de Gramsci salienta que "para comprender bien la conexión que tienen entre sí los estudios escritos en prisión, hay que partir, en primerísimo lugar, del desarrollo del pensamiento y de la acción de Gramsci en el momento en que las puertas de la prisión se cerraron tras él". Desse modo é possível identificar duas situações dessas palavras. A primeira é que o pensamento de Gramsci pode ser identificado como antes e depois dos Cadernos. Desse modo é também possível identificar a combinação entre o desenvolvimento e o amadurecimento do seu pensamento, por meio da sua atividade política cultural. Essa combinação é que irá percorrer o processo de transição para a sua maturidade intelectual e como dirigente político. Nesse processo de transição identifico a segunda situação, Gramsci era um homem 
da ação, e depois um teórico. Essas duas situações já são possíveis identificar na criação do Jornal Ordine Nuovo.

Fundado em $1^{\circ}$ de maio de 1919, o jornal situa-se entre os anos de 1919-1920 com um impulso revolucionário, cuja base nutre-se da experiência Russa. Segundo Rapone (2014) a experiência revolucionaria russa reforça, em Gramsci, a convicção de que a situação sociopolítica na Itália, no momento, estava objetivamente madura para uma nova organização operária. Criado nesse impulso revolucionário a finalidade de sua criação foi difundir a cultura socialista, enquanto elemento essencial e fundante para a luta operária, com vistas a preparar e instituir as condições para as transformações socialistas. Para Coutinho (1999) essa finalidade acentua a transição do seu pensamento e posicionamento sobre a Revolução de Outubro como uma ocorrência que cria elementos para a revolução na Itália.

A Revolução Soviética revelara a Gramsci, na prática, algo que ele já vinha proclamando em teoria: a vontade revolucionária, a inciativa de um sujeito coletivo organizado, pode fazer triunfar as propostas do socialismo mesmo onde as condições objetivas (entendidas segundo uma ótica estritamente economicista) parecem não estar "maduras" para a transformações. (COUTINHO, 1999, p. 27).

Autores como Fiori, (1979); Natoli, (2010); Rapone, (2014) situam o contexto vital da práxis gramsciana a partir de 1914, período que começou o estado de guerra para os italianos, ${ }^{2}$ cujo duração foi de quatro anos, vindo acarretar para o país sérios problemas de ordem política e econômica. Na ordem política, segundo Staccone (1993, p. 17-18), os vários partidos, existentes, eram contrários a essa guerra, por motivos diferentes.

\begin{abstract}
Os liberais, por razões de avaliação prática da consistência do sistema político europeu e da duração da guerra, acreditavam que: primeiro, com a dissolução do império austríaco, haveria uma profunda redefinição da geografia política do continente, da qual o Estado italiano poderia beneficiar-se; segundo a guerra seria longa e dispendiosa, e o Estado italiano não estava preparado para arcar com os gastos, nem sequer de um conflito de curta duração. Para o posicionamento dos socialistas sobressaíam-se as motivações ideológicas, a guerra seria um subproduto da competição econômica capitalista e uma "festa" para os empresários da indústria bélica; e mais realisticamente defendiam a tese de que seria mais útil à população investir recursos na infra-estruturas básicas ao invés de entregar a nação ao massacre e às privações da guerra. O neutralismo dos católicos alimentava-se de outras razões, sobretudo duas: uma, digamos geopolítica, pois a Áustria forte seria um dique e baluarte defendendo a Europa do ameaçador Oriente (leia ortodoxos turcos!); e a outra, mais cultural, pretendia-se a ligação do catolicismo com o mundo camponês tradicionalmente avesso às guerras e às subversões da ordem estabelecidas.
\end{abstract}

Na ordem econômica, nas palavras de Sarti (1973, p. 27) sustenta que:

\begin{abstract}
La Primera Guerra Mundial abría nuevas posibilidades económicas y políticas a la gran industria. Pese a que ni la ASIA ni la Confederación Italiana de la Industria instaban al gobierno a que abandonase su inicial neutralidad en el conflicto, había grupos industriales, como los productores de acero, los fabricantes de armamento y los constructores de barcos que, individualmente, eran intervencionistas. La guerra brindaba oportunidades que todos los industriales se sentían prestos a aprovechar. Manufacturas y finanzas se acercaron más aún de lo que estaban antes de la guerra para formar gigantescas sociedades, necesarias para sufragar los gastos de la guerra.
\end{abstract}

\footnotetext{
2 Para uma compreensão, embora resumida, do porquê da participação dos italianos na guerra e suas consequências para a Itália, consultar: SALVATORELLI, Luigi. Sommario della Storia d'Itália, pp.493-504.
} 
Industriales y funcionarios del gobierno se sentaron a una misma mesa, aprendiendo a estimar las ventajas del planeamiento y la cooperación económica. Nunca hasta entonces los industriales se habían acercado tanto al foco del poder político ni habían estado tan implicados en el proceso de la toma de decisiones.

Na ocasião de julho de 1920 Gramsci (2004) escreve um informe sobre o movimento turinense dos conselhos de fábrica e a produção industrial na cidade de Turim, esclarece que houve homogeneização entre a indústria metalúrgica e a automobilística, o que proporcionou o aumento considerável de operários. Em sua compreensão essas novas possibilidades, na grande indústria, centralizaram o processo produtivo na cidade de Turim, vindo aprofundar, acentuadamente, os conflitos de classe entre proprietários dos meios de produção e os proletários, possibilitando um dos caminhos para a ação revolucionária, por meio, dos sindicatos e comitês de fábricas, que neste período encontravam-se bem estruturados.

Segundo Gramsci (2004) os anos de 1919 e 1920 foram marcados como sendo os anos da possível revolução socialista. Houve crescimento nos vários segmentos sociais ligados às indústrias, como também, um início de organização política de camponeses e trabalhadores sem propriedades, que vieram pedir a reforma agrária. Neste período, muitas greves estouraram, abalando a economia do país. Houve uma repercussão considerável para os industriais, e a classe média aliou-se ao jovem movimento fascista que no período de 1919 a 1922, obtiveram fortalecimento numérico e político notável.

Baseado nestes fatos e outros, Gramsci concluiu em o movimento turinense dos conselhos de fábrica e a produção industrial, na cidade de Turim está presente o germe dos conselhos de fábrica e, também, a vertente para o exercício revolucionário.

Conforme analisa Buci-Gluckmann (1975) os anos de 1916 a $1921 \mathrm{com}$ a guerra o aparelho econômico toma novas direções; transformam-se em um fenômeno simplesmente financeiro com a intervenção mais aparente do Estado, as fábricas passaram a unir-se com os bancos o Estado veio ser o único proprietário do trabalho assumindo a função administrativa, principalmente no setor produtivo. Acrescenta um fato relevante em relação ao aspecto financeiro, do pós-guerra, a unificação dos interesses industriais, feita pelo banco. Sendo o Estado o grande organizador e regulador desses interesses, tornando-se a máquina da acumulação do capital, e o controlador do capital industrial e financeiro.

\section{PROGRAMA DO SEMANÁRIO I'ORDINE NUOVO: A CONQUISTA DO ESTADO}

No semanário L'Ordine Nuovo, enquanto a primeira canalização revolucionária, cujo início é de abril de 1919. Fundado, por quatro personagens relevantes, no cenário político italiano do pós-guerra: Antonio Gramsci, Umberto Terracini, PalmiroTogliatti e Angelo Tasca. L'Ordine Nuovo, um jornal de resenha de cultura socialista semanal, tinha como primeira finalidade difundir essa cultura, a fim de preparar ideologicamente o trabalhador para que o mesmo pudesse criar condições de transformações. O jornal, por sua vez, proporcionou uma relação dialética educadora entre os operários e a comissão 
interna de fábrica vindo a constituir-se o veículo de informações para o operariado fabril. A partir desse encontro, nas palavras de Gramsci (2004, p. 404)

\begin{abstract}
L'Ordine Nuovo não era frias arquiteturas intelectuais, mas brotavam da nossa discussão com os operários melhores, elaboravam sentimentos, vontades, paixões reais da classe operária de Turim, que tinham sido pôr nós ensaiadas e provocadas, porque os artigos de L'Ordine Nuovo eram quase em "atuar" de acontecimentos reais, vistos como momentos de um processo de íntima libertação e expressão de sí própria por parte da classe operária. Eis por que os operários gostaram de L'Ordine Nuovo e eis como se "formou" a idéia de L'Ordine Nuovo".
\end{abstract}

Em 12 de julho de 1919 Gramsci (2004) escreveu o texto a Conquista do Estado, extremamente contundente, no qual visava elaborar um projeto político que viesse criar uma ação revolucionária de ruptura com o Estado burguês. Segundo Gramsci (2004, p. 262)

[...] a formula 'conquista do Estado' deve se entendida no seguinte sentido: criação de um novo
tipo de Estado, gerado pela experiência associativa da classe proletária, um Estado que deve
substituir o Estado democrático-parlamentar.

Nesse texto, Gramsci não só denuncia as potencialidades teóricas fundadoras do Estado burguês, como também visa apontar para o novo Estado apoiado nas várias instituições proletárias. Entende que é necessário a tomada de consciência desse projeto pela classe trabalhadora, tendo em vista que o individualismo, juntamente com a competição, não viabiliza a tomada do poder. A finalidade, segundo Gramsci (2004) desta tomada de consciência é mudar o habitus e a psicologia do operário e camponês, para que comecem a pensar e agir solidariamente, criando um alicerce que venha possibilitar a conquista do Estado. Em o movimento turinense dos conselhos de fábrica e a produção industrial, Gramsci insiste na solidariedade entre os operários e camponeses, constata que tanto os partidos como, também, os sindicatos são incapazes de anunciar uma postura revolucionária contra o Estado democrático-parlamentar. Isto porque a natureza do sindicato é de concorrência, e não comunista.

Através das circunstâncias nascidas da crise do pós-guerra, a concentração capitalista, determinada pelo seu modo de produção converge em uma grande concentração de trabalhadores assalariados, esclarece Gramsci (2004) em o movimento turinense dos conselhos de fábrica e a produção industrial a ocorrência da retomada dos "comunistas marxistas" no empreendimento de uma nova investida revolucionária.

Segundo a análise de Grisoni e Maggiori, (1974, p. 231) para Gramsci a crise, no que se refere ao seu aspecto estrutural e orgânico consiste em um

\footnotetext{
[...] fenômeno interno do bloco histórico, isto é, o conflito de poder está entre os grupos dominantes e seus auxiliares. Já a crise orgânica é uma "desagregação do bloco histórico, no sentido em que os intelectuais, encarregados de fazer funcionar o vínculo estruturasuperestrutura, se afastam da classe a que estavam organicamente ligados e deixam de permitir à sociedade o exercício da sua função hegemônica sobre o conjunto da sociedade: $A$ classe dominante perdeu o consenso, isto é, deixou de ser "dirigente" para se tornar "dominante", detentora da pura força coerciva".
}

A constatação da crise, por Gramsci, instigou a elaborar práticas revolucionárias junto aos trabalhadores, isto porque, no período do L'Ordine Nuovo, o ato revolucionário, para ele consistia em: 
[...] destruir todo aparelho de poder econômico e político, em que as forças produtivas se encontravam reprimidas pela opressão (...) em destruir a máquina do Estado burguês e em constituir um tipo de Estado nos esquemas do qual as forças produtivas libertadas encontram a forma adequada ao desenvolvimento posterior, a sua expansão posterior, na organização do qual encontram a defesa e as armas necessárias e suficientes para suprimir os adversários (Gramsci 2004, p. 324).

Segundo Buci-Glucksmann (1975) com a preocupação em conquistar o Estado burguês, faz com que Gramsci caminhe por outra direção, contrária à estratégia dos partidos socialistas que aceitam a convivência com a democracia burguesa. Para Coggiola (1996) ao analisar, os Bolchevismo, Gramsci, e os Conselhos, mostra que o filósofo sardo irá buscar o seu paradigma revolucionário nos sovietes russo, embora seja possível a constatação, deste modelo, já em Democracia Operaria (2014, p.249).

\begin{abstract}
A ditadura do proletariado é a instauração de um novo Estado, tipicamente proletariado, no qual confluem as experiências institucionais da classe oprimida, no qual a vida social da classe operária e camponesa se torna sistema difundido e fortemente organizado. Este Estado não se improvisa: os comunistas bolcheviques russos trabalharam durante oito meses para divulgar e tornar concreta a palavra de ordem "todo o poder aos sovietes"; e os operários russos conheciam os sovietes desde 1905. Os comunistas italianos devem assimilar a experiência russa e economizar tempo e trabalho: a obra de reconstrução exigirá tanto tempo e tanto trabalho que a ela devem ser dedicados cada dia e cada ano.
\end{abstract}

Na análise de Buci-Gluckmann, (1975) o modelo revolucionário oriundo do L'Ordine Nuovo, não se limita apenas a textos de Lenin, mas também ao movimento alemão, e o britânico dos Shop Stewards Commitees. O que é importante, neste momento, é a denúncia feita, por meio do programa do L'Ordine Nuovo, ao Estado burguês e sua ação contra o operariado italiano, tanto da indústria como do campo. Inerente a esta denúncia visa criar uma consciência revolucionária, através das várias instituições proletárias, mas principalmente, a do Conselho de Fábrica. No L'Ordine Nuovo, Gramsci visa despir o conceito de revolução de todo seu conteúdo messiânico, para tanto, faz uma análise científica das condições da classe operária de Turim e sua relação com a burguesia, tendo em vista apontar algumas diretrizes para emancipação da classe operária. Para ele a classe operária torna-se revolucionária, por encontrar, também, um novo paradigma para este exercício, a fábrica. Nesse sentido, mostra Macciotta ${ }^{3}$ (1975, p. 173-174) dois elementos fundamentais para entender esse novo momento conjuntural e, teórico do filósofo sardo:

[...] por um lado, a novidade do sistema que vai nascer a partir da revolução e do outro a sua continuidade com o passado. A consciência teórica do novo sistema social fundado no proletariado Ihe permite diferenciar o reformismo atual do socialismo italiano, mas a certeza de que o processo revolucionário está conectado com o desenvolvimento das condições históricas de uma determinada sociedade levou-o a assumir uma posição muito crítica em relação ao maximalismo tradicional.

\footnotetext{
3 Todas as traduções do italiano para o português são de minha autoria e são livres.
} 


\section{DEMOCRACIA OPERÁRIA}

Em 21 de junho de 1919 Gramsci (2004) escreve Democracia Operária tendo em vista os acontecimentos históricos, analisados por ele. Nesse mesmo período o filósofo visa articular pensamento e ação entre os operários e, por outro lado, desencadear um processo de educação recíproca entre os trabalhadores e a nova sociedade emergente com a finalidade de desarticular o Estado burguês, cuja função centra-se na regulação do capital industrial e financeiro. Neste texto, Gramsci enfatiza a necessidade de articular as comissões internas de fábrica, por entender, serem elas o ponto inicial do processo revolucionário e por estarem localizadas na fábrica, lugar considerado por Gramsci o lócus, por excelência, direto e concreto da dominação burguesa sobre a classe operária. Essa constatação irá motivar Gramsci a construir a democracia no chão da fábrica, através do fortalecimento das instituições de tipo proletário. Por meio, do processo de fortalecimento é que seria efetivada uma nova sociedade. Dias (2000) ao referir-se sobre a problemática do controle operário e democracia, em Gramsci, mostra que este controle é o elemento fundamental para a efetivação do poder operário. Na concepção de Gramsci, a Democracia Operária não passaria pelo parlamento, nem tampouco, pela representação parlamentar, mas pelas instituições do tipo proletário, tais como, conselhos de bairro, que têm como finalidade aglutinar todos os trabalhadores e teriam por tarefa ampliar-se em comissões urbanas, com objetivos de formar uma teia nacional de representação e organização maior. Conforme analisa Joll (1979, p. 32) a democracia operária,

[...] significava envolver os trabalhadores nas decisões tomadas pelos seus líderes, os "comissários" eleitos pelos membros dos Conselhos, cuja autoridade provinha dos que os haviam eleito mas sujeita a cancelamento caso estivessem em minoria. Implícita em toda essa estrutura estava a idéia - que mais tarde Gramsci tornaria uma parte central de sua filosofia política - de que, através da educação e do esclarecimento, é possível persuadir as pessoas a aceitar espontaneamente decisões e idéias formuladas por seus líderes.

Neste sentido, Democracia Operária visava organizar e aglomerar todos os representantes de todos os grupos para luta e não para limitá-los a nenhum programa partidário, mas exclusivamente para a classe operária de forma democrática. O que Gramsci estava viabilizando era a nova sociedade através e a construção do Estado Operário. Porém, lembra Buci-Gluckmann (1975) sobre a reviravolta dos anos de 1918-1920: Estado e estratégias dos conselhos, que a experiência de um governo operário teve seu início em 1906, quando as famosas commissioni interne di fabrica já tinham um papel reivindicador junto aos proprietários. Gramsci em Democracia Operária mostra que as comissões são limitadas e pouco representativas no que tange à democracia operária. Observa que nas comissões internas há o germe para o início da tomada de poder do Estado burguês, embora visse suas limitações para tanto. A função das comissões internas é somente de reivindicação, é necessário que elas exerçam o poder político, através de sua transformação em nível econômico, isto é, transformando-se em associações produtoras e, em nível político, como organismo de poder. Embora, fazendo essa constatação, para Gramsci, era necessário articular as comissões internas, pois são elas o germe da democracia operária, no processo revolucionário, por estarem localizadas na fábrica. 


\section{REVOLUÇÃO E CONSELHO DE FÁBRICA}

Parece-me que a inserção dos Conselhos de Fábrica nas indústrias italianas, como agente revolucionário, se dá através de várias constatações feitas pelo próprio filósofo sardo.

Uma das primeiras constatações está em seu artigo Sindicatos e Conselhos, de 11 de outubro de 1919, quando discute a Crise Constitucional da Confederação dos Trabalhadores, ligada a crise do Estado Democrático. Gramsci (2014, p. 285), no artigo, analisa os aspectos conjunturais nos quais estão inseridos os sindicatos e conselhos o que permite entender, entre outras coisas, que "a crise é a crise do poder e da soberania".

Na sua análise chega, também, à conclusão de que os líderes, que organizam o aparato sindical juntamente com a classe operária, não percebem essa crise, porque ambos não estão enquadrados na sua real estrutura histórica e, também, estão adaptados a esta estrutura. Entende, ainda, que os Sindicatos dos Profissionais as Câmaras do Trabalho, as Federações Industriais e a Confederação Geral do Trabalho são tipos de organização proletária específico do período da história dominada pelo capital, sendo parte integrante da sociedade capitalista.

Esta constatação que é pertinente permite-lhe delinear uma nova postura revolucionária, isto é, o derrubamento dessa ordem social estabelecida, em crise, através da instauração da ditadura do proletariado que será, no seu entender, encarnado pelos Conselhos de Fábrica.

Mas, em que consiste esse ato revolucionário? É o próprio comunista sardo quem da a resposta em seu artigo o Conselho de Fabrica publicado em 05 de junho de 1920.

\footnotetext{
[...] o ato revolucionário, que consiste num esforço orientado no sentido de quebrar violentamente estes quadros, de destruir todo o aparelho de poder econômico e político em cujo interior as forças produtivas revolucionárias estavam contidas de modo opressivo; que consiste também no esforço orientado no sentido de quebrar a máquina do Estado burguês e de constituir um tipo de Estado cujos quadros as forças produtivas liberadas encontrem a forma adequada ao seu desenvolvimento e expressão ulteriores, em sua organização encontre a garantia e as armas necessárias e suficientes para suprimir seus adversários (Gramsci, 2004, p. 363).
}

Segundo Coggiola (1996) através da análise, de Gramsci os conselhos passam a ter uma consistência relevante para a tomada do poder, pois passam a unir representantes de todos os grupos para a luta. O próprio Gramsci irá chamar a atenção para essa aglutinação dos vários grupos, via Conselhos de Fábrica que estão também baseados nas profissões e seção. A unidade na fábrica, por seção, tem um papel fundamental, neste processo, pois o que Gramsci está propondo é uma novidade, ou seja, que a produção parta da fábrica para que possa paulatinamente acampar no campo das superestruturas políticas vindo a encarnar a ditadura proletária em suas engrenagens gerais.

Gramsci, segundo Coggiola (1996) entendia, ainda, que a força revolucionária dos Conselhos de Fábrica estava sendo constituída através de uma nova compreensão das relações sociais e de produção dos trabalhadores da indústria e do campo. É nesses trabalhadores que estão a capacidade 
de controlar a produção e a comercialização, consequentemente substituindo a burguesia no que se refere à economia e à direção da sociedade.

Só os Conselhos de Fábrica, embora em sua fase inicial, seriam capazes de realizar uma contraofensiva, para fundar um novo tipo de Estado, o Estado socialista, pois nem os partidos políticos e sindicatos seriam no momento capazes de serem instrumento para fundar tal Estado.

Em outro texto Sindicalismo e Conselhos, de 08 de novembro de 1919, enfatiza a falência do sindicato. Ao fazer tal constatação, Gramsci não perde de vista a importância do sindicato como agente reivindicador da classe operária, até porque enfatiza a legalidade industrial como conquistada e enorme ganhos pelos operários, porém isto não é definitivo, pois segundo Gramsci $(2004$, p.126) " $O$ conselho é a negação da legalidade industrial". Na compreensão do marxista sardo, só os Conselhos de Fábrica poderiam destruir a legalidade industrial burguesa, para construir uma nova, transformando o assalariado em produtor tanto no que se refere aos aspectos econômicos como também na esfera psicológica, cultural e política.

Conforme analisa Grisoni e Maggiori (1974, p. 139-140),

[...] para Gramsci, os conselhos de fábrica, representam não só a célula embrionária do Estado Proletário mas também, permitem ao trabalhador que tome consciência do seu ser, se compreenda como produtor e perceba a complexidade do sistema de organização política do Estado. Os consigli educam política e ideologicamente; por meio deles, o operário torna-se o gestor da unidade de produção/fábrica e o gestor da unidade poder/ Estado. Neste sentido, o "movimento dos Conselhos", foi autêntico movimento revolucionário que, além de ter derrubado a legalidade burguesa, ao criar um poder dentro do poder, um Estado dentro do Estado - porque, ao contrário da interpretação clássica, não foram um poder justaposto, isto é, um poder operário que se desenvolvia ao lado de poder burguês, mas um poder operário que subverteu, de dentro, o poder burguês, revolucionava as "mentalidades", derrubava os tabus tradicionais da "incapacidade proletária, sendo a classe operária comumente considerada como incapaz de tomar nas mãos o seu próprio destino e assumir a direção do Estado e, portanto, produzia, no fim de contas, ao mesmo tempo que uma revolução de caráter político uma outra de caráter ideológico, uma revolução cultural.

É perfeitamente aceitável dizer que Gramsci foi original no que se refere à Revolução, via Conselhos de Fábrica. A sua contribuição está no fato de trazer novos elementos para a análise dos Conselhos. Enfatizou que a hegemonia está latente no mundo da produção, daí a necessidade de controlá-la. A hegemonia não tem só uma dimensão cultural, ela é também econômica. Neste sentido, enfatiza a necessidade de se construir uma "vontade coletiva", através da auto-organização dos trabalhadores nas fábricas, via Conselhos. Dizia que a hegemonia nascia na fábrica; portanto, era na fábrica que deveria começar a construir a sociedade socialista.

\section{L'ORDINE NUOVO: UMA REVISTA, UMA ESCOLA}

No entendimento de Gramsci, o período do pós-guerra permitiu um avanço revolucionário e proletário na Itália. Segundo Garratana (1975) este avanço está ligado às eleições de novembro de 1919, quando os partidos socialista e popular (católicos) conseguiram um grande número de eleitos, somando um total de 256 deputados, sendo: 156 socialistas e 100 católicos. Essas eleições determinaram o fim do predomínio dos partidos liberais, os quais representavam as elites econômicas. 
Tal acontecimento era entendido por Gramsci como sendo as novas possibilidades para o processo revolucionário, porém seria necessária uma visão clara da situação que o Partido Socialista Italiano PSI, não tinha.

Segundo as análises de Gramsci em Democracia Operária (2004) aponta para a relevância da direção política, contempla a necessidade de dominar as internas forças sociais que a guerra desencadeou:

Impõe-se hoje um instigante problema a todo socialista que sinta como algo vivo o sentido da responsabilidade histórica que incumbe à classe trabalhadora e ao Partido que representa a consciência crítica e operante da missão desta classe. Como dominar as imensas forças sociais que a guerra desencadeou? Como discipliná-las e dar-lhes uma forma política que tenha em si a virtude de desenvolver-se normalmente, de contemplar-se continuamente, até tornar-se a ossatura do Estado socialista no qual se encarnará a ditadura do proletariado? Como ligar o presente ao futuro, satisfazendo as urgentes necessidades do presente e trabalhando de modo útil para cria e "antecipar" o futuro? (GRAMSCI, 2004, p. 245).

Esta constatação permite a Gramsci insistir na integração entre teoria e prática, isto no mundo do trabalho industrial moderno, ou seja, na fábrica. No entendimento de Nosella, (1992, p. 31-32)

Do ponto de vista teórico-cultural, a primeira grande questão, obviamente, era como integrar teórica e praticamente o mundo do trabalho com um mundo da cultura; a ciência produtiva com uma ciência humanística; a escola profissionalizante com a escola desinteressada. Essa questão devia ser resolvida radicalmente e, para que isso ocorresse, o ponto de partida devia ser único. Gramsci havia aprendido, no estudo dos filósofos da imanência (idealismo), que se o ponto de partida da epistemologia não fosse único, jamais aquela filosofia de livraria do bipolarismo ou da dicotomia. Este único ponto de partida, obviamente, era, na concepção gramsciana, o trabalho industrial moderno, a fábrica.

É importante compreender esse novo fato à luz dos acontecimentos políticos na Itália ${ }^{4}$, pois é nesse período que Gramsci irá romper com a Escola da Cultura em função do "enquadramento" com a experiência russa. Esclarece Manacorda (1975, p. 243-244)

A revolução russa provoca nestes anos um lento esclarecimento dentro do movimento operário tanto no seu conjunto quanto em relação às consciências individuais. A vida política italiana radicaliza - se cada vez mais; ocorre inicialmente a adesão do partido socialista à Terceira Internacional, depois o movimento dos Conselhos de Fábrica, a ocupação da fábricas, a constituição da fração comunista e, finalmente, o nascimento do Partido. Comunista Italiano, com suas primeiras e difíceis opções e suas lutas internas. Gramsci está no centro desses acontecimentos: ele ali está desde 5 de maio de 1919, como o primeiro Ordine Nuovo (semanal e, a partir de janeiro de 1921, diário) que acompanha o movimento dos Conselhos; ali está, com as incertezas que o impediram, talvez, de intervir com iniciativa autônoma no momento em que surgiu o novo partido; está ali, sobretudo, como anteriormente, com a atividade de organização e promoção cultural: a Escola de Cultura e Propaganda Socialista, criada em novembro de 1919, em torno da revista; o Grupo de Educação Comunista, organizado em agosto de 1920; o, Instituto de Cultura Proletária, seção italiana do Proletkult, fundado a 14 de janeiro de 1921. Posteriormente, em maio de 1922, a viagem a Moscou, onde passará a fazer parte da direção executiva da Internacional, afastando - o da Itália pôr dois anos, precisamente no momento da crise decisiva que levará à tomada do poder pelo fascismo.Característica deste período é a insistência prática e [positiva de Gramsci sobre os temas da organização da cultura, sua passagem da crítica negativa da escola burguesa e da política socialista à busca de realizações positivas, que o exemplo do socialismo russo sugere e parece tornar concretamente possíveis.

\footnotetext{
4 Para uma compreensão histórica desses acontecimentos políticos na Itália, consultar as seguintes obras de Paolo Spriano. Storia del Partido comunista italiano. Capítulos I, II, III, IV, V e VI e Storia di Torino operária e socialista. Da De Amicis a Gramsci. Capítulos XXII, XXIII e XXIV.
}

Reflexão e Ação [ISSN 1982-9949]. Santa Cruz do Sul, v. 26, n. 1, p. 197-213, jan./abr. 2018. https://online.unisc.br/seer/index.php/reflex/index 
É possível verificar que, nesse período, a postura de Gramsci é marcada por um novo discurso que passa da crítica negativa da escola burguesa a uma nova assimilação das experiências positivas dos russos, como salienta Manacorda (1975, p. 245):

Nasce neste momento, no pensamento de Gramsci, aquela nova dimensão internacional que, ainda que não seja quantitativamente predominante em suas obras, é, todavia um elemento que não pode ser subestimado se quisermos compreender corretamente a tendência real de sua busca, sem a imagem tradicional que nos fazem dele. E essa dimensão, pôr assim dizer, espacial, acarreta também o ampliar - se temporal, através da qual o homem da província, o meridional, o historiador apaixonadamente mergulhado nas tradições, será depois capaz de desenvolver um discurso pedagógico moderno e de indicar perspectivas de futuro.

Ao assumir essa nova experiência, Gramsci dá um novo enfoque à concepção de Escola, que passa pela reformulação do próprio conceito de escola burguesa a partir da escola Russa. Nessa reformulação há novos dispositivos que estão presentes nesta nova fase. Segundo o parecer de Manacorda (1975) há dois momentos: o primeiro está ligado à crítica do programa burguês de escola; o segundo, à preservação da concepção de "cultura humanística" da escola.

Gramsci em seu artigo homens ou máquinas? de dezembro de 1916, faz uma discussão que contém propostas sobre programas de ensino profissional, já está convencido desta nova concepção de "cultura humanística" que, nesse momento já estava relacionada com a emergência do industrialismo italiano, sendo assim, há uma nova concepção de escola, cujo cerne é o proletariado.

\begin{abstract}
O proletariado precisa de uma escola desinteressada. Uma escola na qual seja dada à criança a possibilidade de ter uma formação, de tornar-se homem, de adquirir aqueles critérios gerais que servem para o desenvolvimento do caráter. Em suma, uma escola humanista, tal como a entediam os antigos e, mais recentemente, os homens do Renascimento. (...) A escola profissional não deve se tornar uma incubadora de pequenos monstros aridamente instruídos para um oficio, sem ideias gerais, sem cultura geral, sem alma, mas só com o olho certeiro na mão firme. Mesmo através da cultura profissional é possível fazer com que surja da criança o homem. Contanto que se trate de cultura educativa e não só informativa, ou não só prática manual (GRAMSCI, 2011, p.58).
\end{abstract}

Segundo Lombardi (1972, p. 69-70) este humanismo não é literário, erudito ou tradicional, mas um humanismo de "tipo novo, isto é, de tipo histórico, que tem suas raízes no contexto e nas atividades do homem, que o converte de sujeito passivo para protagonista da história".

Nesse momento, o filósofo sardo retoma e destaca um novo humanismo na escola, que deve ser um veículo de ligação entre o mundo do trabalho e a construção de um novo homem. Porém, ressalta que essa nova concepção não tem como finalidade descartar o conhecimento acumulado, mas conformá-lo com os novos valores e exigências da sociedade industrial; romper com o caráter unilateral próprio da sociedade burguesa, em que o patrimônio cultural (enciclopédico) era propriedade de poucos privilegiados.

Nesse novo humanismo proposto por Gramsci a função da escola é assumir a tarefa educativa que a escola burguesa perdeu, ou seja, desvinculou os valores transmitidos por um trabalho milenar do pensamento (humanismo enciclopédico), da sociedade real, convertendo-os em objetos alheios à vida cotidiana dos homens. Essa constatação permite-lhe preocupar-se em superar a dualidade entre cultura humanística e cultura técnica estando em sintonia com a emergência da nova sociedade com 
base industrial, que na sua compreensão proporciona, também, um novo tipo de intelectual. Nos Cadernos do Cárcere, Gramsci ao referir-se sobre semanário L'Ordine Nuovo salienta:

\begin{abstract}
Neste sentido trabalhou o semanário L'Ordine Nuovo, visando a desenvolver certas formas de novo intelectualismo e a determinar seus novos conceitos; e essa não foi uma das razões menores de seu êxito, pois uma tal colocação correspondida a aspirações latentes e era adequada ao desenvolvimento das formas reais de vida. O modo de ser do novo intelectual não pode mais consistir na eloquência motor exterior e momentâneo dos afetos e das paixões, mas num imiscuir-se ativamente na vida prática, como construtor, organizador, "persuasor permanente", já que não apenas orador puro e superior, todavia, ao espírito matemático abstrato; da técnica-trabalho, eleva-se à técnica-ciência e à concepção humanística histórica, sem a qual se permanece "especialista" e não se chega a "dirigente" (especialista + político) (GRAMSCI, 2000, p. 53).
\end{abstract}

Embora se preocupe com uma nova cultura técnica, não perde de vista a importância dos valores humanísticos que, na sua concepção, só serão adquiridos através da superação da diferença entre trabalho intelectual e trabalho manual, ${ }^{5}$ presente na concepção burguesa de escola.

Nesse período, a cultura estaria passando a ter um significado bastante amplo, ou seja, não é um simples saber enciclopédico. Em 29 de Janeiro de 1916, Gramsci escreve um artigo Socialismo e Cultura, em que esclarece as diretrizes do que vem a ser a concepção de cultura para o socialismo, pois esta mesma concepção que irá nortear todo o seu pensamento, tanto no L'Ordine Nuovo, como também nos Cadernos do Cárcere.

\begin{abstract}
É preciso perder o hábito e deixar de conceber a cultura como saber enciclopédico, no qual o homem é visto apenas sob a forma de um recipiente e encher e entupir de dados empíricos, de fatos brutos e desconexos, que ele depois deverá classificar em seu cérebro como nas colunas de um dicionário, para poder em seguida, em cada ocasião concreta, responder aos vários estímulos do mundo exterior. Essa forma de cultura é realmente prejudicial, sobretudo para o proletariado. Serve apenas para criar marginais, pessoas que acreditam ser superiores ao resto da humanidade porque acumulam na memória um certo números de dados e de datas que vomitam em cada ocasião, criando assim quase que uma barreira entre elas e as demais pessoas. (Gramsci, 2004, p. 57).
\end{abstract}

O conteúdo desta cultura deve ser buscado, na compreensão do marxista sardo, fora da escola burguesa e da estrutura do Estado burguês, nas associações livres de estilos dos sovietes de cultura proletária. Dos novos conteúdos que estariam em gestação, o mais significativo, para os nossos propósitos, é o que diz respeito à fábrica como autogestão para a ditadura do proletariado, pois é nela que se encontra todo o processo de saber para a efetivação da tomada do poder. Daí dizer Gramsci (2004, p. 401) em o programa de L'Ordine Nuovo

É preciso estudar a organização da fábrica como instrumento de produção: temos de consagrar toda nossa atenção aos sistemas capitalistas de produção e de organização e temos de trabalhar para que as atenções da classe operária e do Partido convirjam para tal tema.

Como já assinalamos, anteriormente, a fábrica é, nesse período, o centro da atenção de Gramsci, pois, como verificamos, é nela que está o germe do futuro Estado operário, na medida em que é a célula dos Conselhos de Fábrica. Esse jeito de ver e entender a fábrica permite ao filósofo colocar o problema educativo, não só no prisma da crítica, mas como um problema técnico e político.

\footnotetext{
${ }^{5}$ Esta questão Gramsci irá trabalhar de forma mais consistente nos Cadernos do Cárcere, principalmente número 12, quando atribuía esta superação através da Escola Unitária e o trabalho como princípio educativo. Porém, no período do L 'Ordine Nuovo, já aparece elementos para entendermos esta superação, através da própria proposta do semanário.
} 
Segundo Manacorda (1975) o sentido técnico-político do ato educativo, na fábrica, que está no L'Ordine Nuovo, focaliza uma dimensão dialética do trabalhador, não no sentido de uma "mecanização"do trabalhador, mas dando-Ihe uma nova dimensão e capacidade. Essa compreensão tem o seu ápice, quando Gramsci (1974, p. 111) escreve em 27 de julho de 1919 // problema della scuola em que faz a relação entre escola e trabalho, pautado nos Conselhos de Fábrica.

No Estado dos Conselhos a escola representará uma das mais importantes e essenciais atividades públicas. (...). Pretendemos suscitar uma psicologia de construtores, de companheiros já idealmente organizados no Estado dos Conselhos, já idealmente laboriosos e ativos na criação de todos os organismos da nova vida social.

A relação trabalho - escola, nessa perspectiva, deve abranger todos os aspectos do saber humano, porém esta relação não é uma simples experiência de fazer uma horta nos fundos da escola e nem tão pouco adaptá-la. Para que se concretize a autêntica escola do trabalho, nas palavras de Nosella (1992, p. 37)

\begin{abstract}
O trabalho moderno organicamente se une à escola quando consegue inspirar neste seu espírito de laboriosidade, seu método disciplinar produtivo e de precisão, sua ética de solidariedade universal com os interesses e objetivos de todos, sua lógica produtiva de organização de muitos para um só fim. Esse fim, obviamente, deverá ser diferente, pois escolas produzem algo diferente das fábricas, como aliás também estas não produzem todas as mesmas coisas. A escola produz fundamentalmente trabalho intelectual; a fábrica, trabalho material. Ou seja, a organicidade entre fábrica e escola ocorre (deve ocorrer) a nível de método (no sentido mais profundo) e não a nível de técnicas ou de fim imediato. Em outras palavras, a escola se inspira no trabalho industrial moderno com o seu princípio pedagógico, não certamente deixando de ser escola (nem parcialmente) e sim concretizando-se como uma escola historicamente moderna, isto é, tendencialmente socialista, centrando-se na idéia de atuar a liberdade concreta e universal do homem. E os operários quando vão à escola, não vão para continuar a produzir os mesmos produtos que na fábrica produziam e sim para entender mais profundamente sua fábrica, seu instrumento de trabalho e sua organização produtiva, numa perspectiva histórica, universal e política. Assim, a escola fica a escola e a fábrica fica fábrica, só que a primeira torna-se "escolado-trabalho", enquanto pertence espiritualmente ao mundo do trabalho e pelo trabalho é inspirada; e a oficina torna-se oficina de trabalhadores "intelectuais", porque passou a ser oficina iluminada, humanizada e potenciada pela escola.
\end{abstract}

Podemos dizer, em resumo, que L'Ordine Nuovo inaugura um novo tipo de humanismo, em função da organização social com base no industrialismo, surgido na época, proporcionando uma nova concepção de educação e de escola devendo prevalecer os laços de solidariedade universal, fundamentada na fábrica e no trabalho produtivo. 


\section{CONSIDERAÇÕES FINAIS}

O objetivo do texto foi uma contribuição, introdutória, de alguns dos aspectos do pensamento educacional do filósofo italiano Antonio Gramsci, divulgado no Semanário L'Ordine Nuovo, no período logo após o primeiro grande conflito. A análise trouxe à tona alguns aspectos da crise italiana, a qual, segundo Gramsci possibilitou o amadurecimento da situação revolucionária, na Itália, com o envolvimento de todas as classes sociais e suas contradições no interior da sociedade italiana.

Verificou-se que o movimento do proletariado desenvolveu uma estratégia que tinha o seu início na sociedade e, ao mesmo tempo, apontava para alternativas de tomada de poder que estava na indústria via, conselhos de fábrica. Na estratégia desta constatação é criado L'Ordine Nuovo com a finalidade de difundir a cultura socialista, tendo várias funções: educar o proletariado nesta cultura, denunciar as contradições do Estado burguês e resgatar a concepção da escola-do-trabalho, tendo em vista que é nessa concepção que o proletariado iria "esclarecer" e "reforçar" sua visão de mundo e de trabalho, nessa vertente é que os trabalhadores iriam construir as novas relações, efetivando uma outra concepção de sociedade.

Verificou-se em relação à escola, no período do L'Ordine Nuovo, que ela não seria só um organismo de instrução, mas também um veículo de ligação entre o mundo do trabalho e a construção de um novo mundo, uma cultura nova. Ao propor tal ligação, Gramsci visava superar a dicotomia entre cultura humanística e cultura técnica, posteriormente irá identificar essa superação e separação, por meio, da escola única. 


\section{REFERÊNCIAS}

1. AGGIO, Aggio; HENRIQUES, Luiz Sérgio, VACCA, Giuseppe. (Orgs.) Gramsci no seu tempo. Brasília: Fundação Astrogildo Pereira; co-edição Rio de Janeiro: Contraponto, 2010.

2. BUCCI-GLUCKSMAN, Christinne. Gramsci et L'État: Pour une théorie matérialiste de la philosophie. Paris, Fayard, 1975.

3. COGGIOLA, Osvaldo. Bolchevismo, Gramsci, conselhos. In: DIAS, E. F. (et al.). O outro Gramsci. 2. ed. São Paulo: Xamã, 1996.

4. COUTINHO, Carlos Nelson. Gramsci: um estudo sobre seu pensamento político. Rio de Janeiro: Civilização Brasileira, 1999.

5. DIAS, Edmundo Fernandes. Gramsci em Turim: a construção do conceito de hegemonia. São Paulo: Xamã, 2000.

6. __ (et al.). O outro Gramsci. 2. ed. São Paulo: Xamã, 1996.

7. FIORI, Giuseppe. A vida de Antonio Gramsci. Rio de Janeiro: Paz e Terra, 1979.

8. GARRATANA, Valentino. Prefazione. In: GRAMSCI, A. Quaderni del carcere. Roma: Riuniti, 1975.]

9. GRAMSCI, Antonio. II problema della scuola. In: URBANI, G. (Org.). La formazione dell'uomo: scritti di pedagogia. Roma: Riuniti, 1967. Antonio. Quaderni del carcere. Roma: Riuniti, 1975. Organizado por Valentino Gerratana. Antonio. Cadernos do cárcere. Vol. 2. Rio de Janeiro: Civilização Brasileira, 2004. Antonio. O movimento turinense dos conselhos de fábrica e a produção industrial. COUTINHO, Carlos Nelson. (Org.). Escritos políticos. Rio de Janeiro: Civilização Brasileira, 2004. Vol. 1. Antonio. Sindicalismo e conselhos. In: COUTINHO, Carlos Nelson. (Org.). Escritos políticos. Rio de Janeiro: Civilização Brasileira, 2004. Vol. 1.

14 Antonio. Socialismo e cultura. In: COUTINHO, Carlos Nelson. (Org.). Escritos políticos. Rio de Janeiro: Civilização Brasileira, 2004. Vol. 1. 

Antonio. Democracia operária. In: COUTINHO, Carlos Nelson. (Org.). Escritos políticos. Rio de Janeiro: Civilização Brasileira, 2004. Vol. 1. Antonio. A conquista do Estado. In: COUTINHO, Carlos Nelson. (Org.). Escritos políticos. Rio de Janeiro: Civilização Brasileira, 2004. Vol. 1. Antonio. O conselho de fábrica. In: COUTINHO, Carlos Nelson. (Org.). Escritos políticos. Rio de Janeiro: Civilização Brasileira, 2004. Vol. 1. Antonio. O programa do L'Ordine Nuovo. In: COUTINHO, Carlos Nelson (Org.). Escritos políticos. Rio de Janeiro: Civilização Brasileira, 2004. Vol. 1. Antonio. Sindicatos e conselhos. In: COUTINHO, Carlos Nelson. (Org.). Escritos políticos. Rio de Janeiro: Civilização Brasileira, 2004. Vol. 1. Antonio. Homens ou maquinas?. In: COUTINHO, Carlos Nelson. (Org.). O leitor de Gramsci. Rio de Janeiro: Civilização Brasileira, 2011. GRISONI, Dominique e MAGGIORE, Robert. Ler Gramsci. Lisboa: Iniciativas Editoriais, 1974. JOLL, James. As idéias de Gramsci. São Paulo: Cultrix, 1979.

23. LOMBARDI, Franco. Las ideas pedagógicas de Gramsci. Barcelona: A. Redondo editor, 1972.

24. MACCIOTTA, Giorgio. Rivolucione e Classe Operaia negli Scritti sul' "Ordine Nuovo". In: GARIN, Eugenio; ROSSI, Pietro (Orgs.) Gramsci e la cultura contemporanea. Roma: Riuniti, 1975, v.2.

25. MANCORDA, Mario Alighiero. La formazione del penseiro pedagogico di Gramsci. In: ROSSI, Pietro (org.) Gramsci e la cultura contemporanea. v. 2. Roma: Riuniti, 1975.

26. NATOLI, Claudio. Grande guerra e renovação do socialismo nos escritos do jovem Gramsci (19141918). In: AGGIO, Aggio; HENRIQUES, Luiz Sérgio, VACCA, Giuseppe. (Orgs.) Gramsci no seu tempo. Brasília: Fundação Astrogildo Pereira; co-edição - Rio de Janeiro: Contraponto, 2010

27. NOSELLA, Paolo. A escola de Gramsci. Porto Alegre: Artes Médicas, 1992.

28. RAPONE, Leonardo. O jovem Gramsci: cinco anos que parecem séculos 1914-1919. Rio de Janeiro: Contraponto; Brasília, DF: Fundação Astrojildo Pereira, 2014. 
29. PROCACCI, Giovanna; BEZZA, Bruno. (Orgs.) Stato e Classe Operaia in Italia durante la Prima Guerra Mondiale. Milano: Franco Angeli, 1983.

GARIN, Eugenio; ROSSI, Pietro (Orgs.) Gramsci e la cultura contemporanea. Roma: Riuniti, 1975.

31. SALVATORELLI, Luigi. Sommario della storia d'Italia: dai tempi preistorici ai nostri. Torino: Einaudi, 1969.

32. SARTI, Roland. Fascismo y burguesia industrial: Italia 1919-1940: un estudio sobre la expansion del poder privado bajo el fascismo. Barcelona: Fontanella, 1973.

33. SPRIANO, Paolo. Storia del partido comunista italiano. Da Bordiga a Gramsci. $2^{\mathrm{a}}$ ed. Torino: Einaudi, 1972.

34. Storia di Torino operaia e socialista. Da Amicis a Gramsci. 4. ed. Torino: Einaudi,1972.

35. STACCONE, Giuseppe. Gramsci:100 anos revolução e política. 2. ed. Petrópolis: Vozes, 1993.

\section{Jefferson Cariello do Carmo}

Mestre e Doutor em Educação Aplicada às Ciências Sociais - UNICAMP, Pós-Doutor em História Social do Trabalho - Departamento de História - UNICAMP. Professor/Pesquisador do Programa de Pós-Graduação em Educação da Universidade de Sorocaba - UNISO. Coordenador do grupo de pesquisa: Instituição Escolar: História, Trabalho e Políticas de Educação Profissional, CNPq. Universidade de Sorocaba - UNISO - Sorocaba - São Paulo - Brasil.

\section{Como citar este artigo}

CARMO, Jefferson Carriello. O pensamento político educacional de Antonio Gramsci antes dos cadernos do cárcere. Reflexão e Ação, Santa Cruz do Sul, v. 26, n. 1, jan/abr. 2018. ISSN 1982-9949. Disponível em: <https://online.unisc.br/seer/index.php/reflex/article/view/8832>. Acesso em: 2018. doi:http://dx.doi.org/10.17058/rea.v26i1.8832. 